reporting systems to identify possible vaccine-related adverse events.

The system requires that all vaccination and medical records are computerized, linked and studied for possible associations. "That way, you have a cohort where you don't have to worry about under- or biased reporting," Chen told Nature Medicine.

According to Chen, chief of CDC's vaccine safety and development program, only a handful of countries outside the US (Canada, the Netherlands and Australia) currently have vaccine-specific surveillance systems in place. Chen has had discussions with health officials in Sweden and the UK about developing such systems and says "they are trying to get the resources to do it."

Overall, the US government receives about 10,000 reports of vaccine-related events annually, "a mix of true reactions and coincidental ones," Chen says. Of these, "fewer than 20 percent are considered serious by the CDC."

Christopher Payne, Department of Public Health, Swansea, UK, who found no significant link between autism and MMR vaccination in a recent population-based study, welcomes a monitoring system. "If a more vigilant surveillance system needs to be put in place to reassure people so that they feel safe with vaccination, then that's what we must do," says Payne. The problem, he says, is that although vaccination histories are maintained nationwide, there is no parallel system that records childhood morbidity. Such events are registered centrally through a different mechanism. In the interim, Payne is advocating an epidemiological study of autism against vaccination status in the UK.

Ironically, one week prior to the release of Wakefield's paper, the CDC reported that 1997 childhood vaccinations were the highest ever, with immunizations for all of the common diseases at well above 90 percent. Failure to immunize, stated the CDC, could lead to outbreaks such as the measles epidemic of 1989-1991 which resulted in 55,000 cases and over 120 deaths. This is, of course, the most troubling reaction to Wakefield's paper. Immunization rates may fall as they did following the 1970s scare over the pertussis vaccine, which was linked to brain damage in infants. Any change in MMR vaccination figures in the UK will become apparent within the next three months.

Karen Birmingham, New York \&

Marlene Cimons, Washington, D.C.

\title{
Slow progress in malaria vaccine development
}

In January, a century and five months after the discovery of the parasite that causes malaria, Genzyme Transgenics Corporation announced the development of a system for producing a promising vaccine against the disease. The company has developed a transgenic mouseline that expresses a modified form of an antigen from Plasmodium falciparum in its milk. Initial trials have suggested that the protein, called

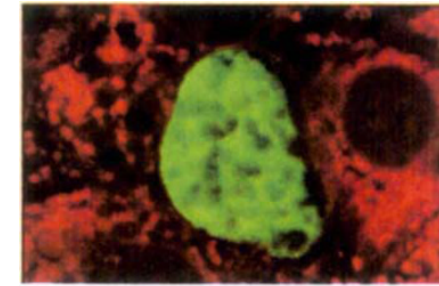

Human hepatocytes infected with $P$. falciparum

pharmaceutical companies historically had some interest in developing vaccines against diseases that affect people in third-world countries." Fortunately, recent government and private initiatives are changing that situation.

One such effort, the Multilateral Initiative on Malaria (MIM), aims to establish close ties between scientists in Africa and other malariaendemic areas and those in developed nations to tailor disease control proMSP-1, can induce a protective immune response against the red blood cell stage of the parasite.

Genzyme's development is not the first attempt by a pharmaceutical company to produce a malaria vaccine (see Table). In recent years, the field has included such giants as SmithKline Beecham, Hoffman-La Roche and Glaxo Wellcome as well as numerous small biotechnology companies. But the most advanced vaccine in terms of clinical trials remains that developed by Manuel Patarroyo from the Immunology Institute in Bogota. Patarroyo has handed over worldwide rights to the SPF66 vaccine

grams to local needs. Participant Berend Mons, says that MIM has enabled "public sector initiatives to be launched to bridge the fatal gap between promising academic results and the point where a capable firm picks up the lead with its own investment."

Stephen Hoffman, a scientist at the Malaria Program of the Naval Medical Research Institute, feels that complaints about a gap between basic and pharmaceutical research may be misplaced. "The real situation is that you have one of the top three infectious diseases in the world for which the overall investment is a pittance, both in the public

\begin{tabular}{|c|c|c|}
\hline \multicolumn{3}{|c|}{ Malaria vaccines in clinical trials } \\
\hline Company/organization & levelopment phase & vaccine type \\
\hline WHO/Manuel Patarroyo & Phase III & SPf66 peptide vaccine \\
\hline Virogenetics (Pasteur Mérieux)/WRAIR & Phase II & NYVAC-Pf7A multivalent vaccine \\
\hline Aquila Biopharmaceuticals/WRAIR & phase I & SPf66 antigen with QS-21 adjuvant \\
\hline Chiron/Medisorb/NIAID & phase I & polypeptide analogue of $\mathrm{Pfs} 25$ \\
\hline Hoffmann-La Roche/ WEHIMR & phase I & recombinant subunit vaccine \\
\hline \multicolumn{3}{|c|}{$\begin{array}{l}C D C=\text { Centers for Disease Control and Protection } \\
\text { WRAIR = Walter Reed Army Institute for Research } \\
\text { NMRI = US Naval Medical Research Institute } \\
\text { WEHIMR = Walter and Eliza Hall Institute of Medical Research } \\
\text { NIAID = National Institute of Allergy and Infectious Diseases }\end{array}$} \\
\hline
\end{tabular}

to the World Health Organization, which has initiated large-scale clinical trials in Thailand, Tanzania, Ecuador and Gambia. But in contrast to other highly-competitive areas of pharmaceutical research, malaria vaccine studies have often ended in suspended trials and abandoned programs, with many companies pursuing the work primarily for its spin-off technologies, such as DNA vaccination.

Such half-hearted interest seems surprising for a disease affecting 300 million people worldwide and killing around two million a year. The economic implications of investing in malaria research, though, have not been encouraging. Patricia Diamond, a spokeswoman for Genzyme, puts it bluntly: "it would be disingenuous to claim that sector and in the private sector," says Hoffman (see Miller \& Hoffman, page 520).

Other malaria researchers point out that control of the disease will probably require the development of a vaccine in addition to more traditional methods, such as distributing mosquito netting. But efforts which focus solely on reducing human-mosquito contact may have an unintended effect, as exposure to the disease currently confers some degree of immunity in tropical areas. "[Vaccines and vector control] will be needed together because many of us are concerned that as immunity drops through the use of netting, then disease will return," explains Louis Miller of the National Institute of Allergy and Infectious Disease.

Alan Dove, New York 